\title{
Au-Pt Nanoparticle Formulation as a Radiosensitizer for Radiotherapy with Dual Effects
}

This article was published in the following Dove Press journal:

International Journal of Nanomedicine

\author{
Song Yang ${ }^{1,2, *}$ \\ Gaohua Han 1,2,* \\ Quan Chen ${ }^{2,3}$ \\ Lei Yu ${ }^{1,2}$ \\ Peng Wang ${ }^{1,2}$ \\ Qi Zhang ${ }^{\mathrm{l}, 2}$ \\ Jiang Dong ${ }^{1,2}$ \\ Wei Zhang ${ }^{2,4}$ \\ Junxing Huang ${ }^{1,2}$ \\ 'Department of Oncology, Taizhou \\ People's Hospital, Taizhou, Jiangsu, \\ People's Republic of China; ${ }^{2}$ Medical \\ School of Nantong University, Nantong, \\ Jiangsu, People's Republic of China; \\ ${ }^{3}$ Department of Thoracic Surgery, \\ Taizhou People's Hospital, Taizhou, \\ Jiangsu, People's Republic of China; \\ ${ }^{4}$ Department of Infectious Disease, \\ Taizhou People's Hospital, Taizhou, \\ jiangsu, People's Republic of China \\ *These authors contributed equally to \\ this work
}

Correspondence: Wei Zhang

Department of Infectious Disease,

Taizhou People's Hospital, No. 399, South

Hailing Road, Taizhou, 225300 Jiangsu,

People's Republic of China

Tel +86-523-86606739

Email zw56265229I@126.com

Junxing Huang

Department of Oncology, Taizhou

People's Hospital, No. 399, South Hailing

Road, Taizhou, 225300 Jiangsu, People's

Republic of China

Tel +86-523-86606739

Email hjxtz@sina.cn
Background: Radiotherapy occupies an essential position as one of the most significant approaches for the clinical treatment of cancer. However, we cannot overcome the shortcoming of X-rays which is the high value of the oxygen enhancement ratio (OER). Radiosensitizers with the ability to enhance the radiosensitivity of tumor cells provide an alternative to changing X-rays to protons and heavy ion radiotherapy.

Materials and Methods: We prepared the Au-Pt nanoparticles (Au-Pt NPs) using a onestep method. The characteristics of the Au-Pt NPs were determined using TEM, HAADFSTEM, elemental mapping images, and DLS. The enhanced radiotherapy was demonstrated in vitro using MTT assays, colony formation assays, fluorescence imaging, and flow cytometric analyses of the apoptosis. The biodistribution of the Au-Pt NPs was analyzed using ICP-OES, and thermal images. The enhanced radiotherapy was demonstrated in vitro using immunofluorescence images, tumor volume and weigh, and hematoxylin \& eosin (H\&E) staining.

Results: Polyethylene glycol (PEG) functionalized nanoparticles composed of the metallic elements $\mathrm{Au}$ and $\mathrm{Pt}$ were designed to increase synergistic radiosensitivity. The mechanism demonstrated that heavy metal NPs possess a high X-ray photon capture crosssection and Compton scattering effect which increased DNA damage. Furthermore, the AuPt NPs exhibited enzyme-mimicking activities by catalyzing the decomposition of endogenous $\mathrm{H}_{2} \mathrm{O}_{2}$ to $\mathrm{O}_{2}$ in the solid tumor microenvironment (TME).

Conclusion: Our work provides a systematically administered radiosensitizer that can selectively reside in a tumor via the EPR effect and enhances the efficiency of treating cancer with radiotherapy.

Keywords: radiosensitizer, nano-enzyme, TME, radiotherapy

\section{Introduction}

Radiation therapy (radiotherapy, RT) is one of the most effective therapies available for the treatment of localized solid cancers. ${ }^{1}$ During radiotherapy of a malignant tumor, biological macromolecules of the tumor cells directly interact with the radiation to generate free radicals which cause damage to the DNA, such as strand breaks, point mutations, and aberrant DNA cross-linking. ${ }^{2-4}$ In addition, the radiation causes water molecules in the tissues to ionize and produce free radicals, which in turn interact with the biological macromolecules to cause cell damage and death. ${ }^{5}$ Theoretically, almost all types of tumors could be effectively controlled when the local radiation dose is high enough. ${ }^{6}$ However, a high dose of radiation induces high toxicity to healthy tissues causing side effects. ${ }^{7}$ Except for the new radiation-delivery techniques that improved the therapeutic effect, highly effective and low-toxicity radiosensitizers are necessary. The 
improvement of the physical technology, for example, brachytherapy, intensity-modulated RT, image-guided RT, and stereotactic RT has greatly improved radiation therapy. ${ }^{8-11}$ However, many problems still remain, such as the complex tumor microenvironment containing cancer stem cells, vasculogenesis, and metabolic alterations. ${ }^{12-14}$

Except for tumor size, the intrinsic radio-sensitivity, cell proliferation, and the extent of hypoxia are important factors for controlling the tumor. ${ }^{15}$ Hypoxia is one of the most important indicators and is related to cancer therapyresistance. $^{16}$ Hypoxia activates the Nrf2 pathway, which leads to anti-oxidant and anti-inflammatory responses with an aggregation of M2 macrophages and MDSCs that protect the tumor. ${ }^{5}$ Owing to the existence of the hypoxic microenvironment of the tumor, the therapeutic efficiency of chemotherapy, radiotherapy and others, are reduced. In recent years, different strategies including physical stimulation (e.g. fractional irradiation) and chemical reaction, have been developed for relieving tumor hypoxia. ${ }^{17,18}$ However, it is difficult to prevent the growth of a tumor using a monotherapy. Due to the reduced side effects and enhanced therapeutic effect of synergistic therapy, it is used to overcome the insufficient tumor suppression effect of monotherapy.

Radiosensitizers are molecules/materials with the ability to enhance the radiosensitivity of tumor cells and provide opportunities to overcome the obstacles mentioned above. ${ }^{2}$ There are many kinds of radiosensitizers, namely small-molecule chemicals, macromolecules, and nanostructures. ${ }^{19}$ One of the most important mechanisms for increasing radiosensitivity is to change the hypoxic microenvironment via different kinds of radiosensitizers. Many tumors are resistant to radiation therapy because they lack oxygen within the tumor due to abnormal or dysfunctional blood vessels. ${ }^{20}$ This state of hypoxia leads to less DNA damage at the same radiation dose. $^{21}$ Therefore, oxygen is a well-known radiosensitizer. ${ }^{4}$ Chemicals and hypoxia-inducing cytotoxins were developed for clinical use because of their oxygen-producing capacity through a mechanism of damage fixation utilizing their electron affinity. ${ }^{22,23}$ Macromolecules are able to regulate the radiosensitivity mechanism by binding with the DNAs, miRNA, mRNAs, siRNAs, proteins or peptides. ${ }^{24}$ Recently, the introduction of nanotechnology has provided momentum and expanded the horizon for the development of radiosensitizers. ${ }^{25}$ In recent years, heavymetal nanomaterials with high atomic numbers $(Z)$ have shown promise as radiosensitizers because they can absorb, scatter, and emit radiation energy. ${ }^{26-28}$ An excellent candidate is gold nanomaterials (AuNPs) because they have tunable morphologies, they are easy to modify, they have good biological safety, and they have exceptional radiation sensitization capabilities. ${ }^{29-32}$ Furthermore, AuNPs are good for drug delivery and cancer therapy. ${ }^{33}$ In addition, various catalase-like nanomaterials have been developed for catalyzing the decomposition of hydrogen peroxide $\left(\mathrm{H}_{2} \mathrm{O}_{2}\right)$ into oxygen, which alleviates tumor hypoxia, and overcomes the hypoxiainduced radioresistance. ${ }^{34}$ Therefore, to develop a simple and effective strategy for relieving the hypoxic tumor microenvironment is essential to improving the therapeutic efficacy of radiotherapy.

In the present study, we designed a nanoparticle composed of the metallic elements $\mathrm{Au}$ and $\mathrm{Pt}$ (Au-Pt NPs). The Au-Pt NPs exhibited enzyme-mimicking activities, which resulted in synergistic radiosensitivity for reinforced tumor therapy. The new Au-Pt NPs with nanozymes were synthesized in one step at room temperature. The nanoparticles produced had a uniform nanosphere shape and were very stable in physiological solutions. After intravenous administration, the Au-Pt NPs passively targeted the tumor and rapidly accumulated in it because of the enhanced permeability and retention (EPR) effect. Not only do the $\mathrm{Au}-\mathrm{Pt}$ nanozymes possess a radiosensitivity ability to enhance the energy deposition of the X-rays but are also able to catalyze the reaction that converts $\mathrm{H}_{2} \mathrm{O}_{2}$ to $\mathrm{O}_{2}$. In addition to attenuating tumor hypoxia, the Au-Pt NPs significantly inhibited tumor growth under 8 Gy of X-ray irradiation compared to the control group. This demonstrated that the Au-Pt NPs improved the therapeutic efficiency of radiotherapy. Therefore, our work developed a novel radiosensitizer with low toxicity, for enhanced tumor radiotherapy by alleviating the tumor hypoxic microenvironment. Our findings highlight the great potential of applying Au-Pt NPs in the future clinical treatment of cancer.

\section{Materials and Methods Synthesis of Au-Pt NPs}

L-proline $0.0384 \mathrm{~g}, 20 \mu \mathrm{L}$ of $\mathrm{HAuCl}_{4}$ and $\mathrm{H}_{2} \mathrm{PtCl}_{6}$ solution $(1 \mathrm{~mol} / \mathrm{L})$ were dispersed in $10 \mathrm{~mL}$ of deionized water. The $\mathrm{pH}$ value of the solution was adjusted to 9 by adding $\mathrm{NaOH}$. Next, ascorbic acid $\left(10 \mathrm{mmol} \mathrm{L}^{-1}\right)$ was added drop by drop. The products were obtained by allowing the solution to react for $20 \mathrm{~min}$ at room temperature. Finally, C18PMH-PEG (10 mg) was added to $10 \mathrm{~mL}$ of an $\mathrm{Au}-\mathrm{Pt}$ 
solution. Au-Pt-PEG-PMH was obtained by stirring the solution for $24 \mathrm{~h}$ at room temperature. After $2 \mathrm{~h}$ of ultrasonication, the mixture was dried by rotary evaporator. Ten $\mathrm{mL}$ of deionized water was added to dissolve the solid which yielded PEGylated Au-Pt nanoparticles (AuPt NPs). The Au-Pt nanoparticle that were obtained were further purified through centrifugation at $6000 \mathrm{rpm}$ for 10 min to remove any incompatible nanomaterials. In addition, the Au-Pt NPs were washed three times through ultrafiltration filters with $100 \mathrm{kDa} \mathrm{MWCO}$ to remove any unbound PEG.

\section{Determining the Characteristics of the Au-Pt NPs}

The hydrodynamic diameters and Zeta potentials of the AuPt NPs suspended in PBS and 10\% FBS were measured by dynamic light scattering (DLS) (Malvern Instruments, UK). The morphology was determined using high-angle annular dark-field scanning transmission electron microscopy (HAADF-STEM), and the characteristics were described from elemental mapping images using a transmission electron microscope (TEM, JEM-1230, Japan).

\section{Detection of $\mathrm{O}_{2}$}

To investigate the efficiency with which oxygen is generated in vitro, the Au-Pt NPs $(50 \mu \mathrm{g} / \mathrm{mL}), \mathrm{H}_{2} \mathrm{O}_{2}(2 \mathrm{mmol} / \mathrm{L})$ were added to $3 \mathrm{~mL}$ of $\mathrm{PBS}(\mathrm{pH} 6.75)$ at room temperature. An oxygen probe (JPBJ-608 portable Dissolved Oxygen Meters, Shanghai REX Instrument Factory) was used to measure the dissolved oxygen concentration every minute for 18 minutes.

\section{Cell Line and Animals}

Cells of the human vascular endothelial cell line HUEVC and murine breast cancer cell line 4T1 were provided by the central laboratory of Taizhou People's Hospital (purchased from the Cell Bank, Shanghai Institutes for Biological Sciences, Chinese Academy of Sciences, Shanghai) and grown in the recommended cell culture medium under the standard conditions. Female BALB/c mice (6-8 weeks) were maintained according to the protocols approved by the Nantong University Laboratory Animal Center. All animal protocols were in accordance with the National Institute's Health Guide for the Care and Use of Laboratory Animals.

\section{In vitro Cell Experiments}

The cell cytotoxicity was determined by the 3-(4,5-dimethyl2-thiazolyl)-2,5-diphenyl-2H-tetrazolium bromide (MTT) assay (Sigma) following the standard protocol. The surviving fraction (SF) of the clone formation assay was calculated after the cells were irradiated with $0,2,4,6$ or 8 Gy X-rays and kept in culture for 10 days. Fluorescence images were obtained of the phosphorylated $\mathrm{H}_{2} \mathrm{AX}\left(\gamma \mathrm{H}_{2} \mathrm{AX}\right)$ in the 4T1 murine breast cancer cells after irradiation for $24 \mathrm{~h}$ and treated with Au-Pt NPs. The radiation source was a RS 2000 with $0.3 \mathrm{~mm}$ copper filter, irradiating at $160 \mathrm{kV}$ at $25 \mathrm{~mA}$ and a dose rate of $1.203 \mathrm{~Gy} / \mathrm{min}$. The fluorescence images were analyzed using Living Imaging software. Live/dead cell discrimination was performed using the Live/Dead Fixable Aqua Dead Cell Stain Kit (Life Technologies) or the Sytox Red Dead Cell Stain (Life Technologies). Cell surface staining was done for 20-30 minutes. Cells were spun down and stained with a 1:200 final concentration of the antibodies in $50 \%$ of a $2.4 \mathrm{G} 2$ (Fc block) and $50 \%$ of a FACS Buffer (PBS $+1 \%$ FBS, 2mM EDTA) for 15 min. Flow cytometric analyses were performed to determine the percentage of apoptotic cells. Cells suspended in PBS containing 1\% FBS were incubated with anti-mouse antibody against Annexin V-FITC and PI for $20 \mathrm{~min}$ at room temperature in the dark and then evaluated using a flow cytometer. All flow cytometry analyses were performed using an LSRFortessa (BD Biosciences) or an LSR-II (BD Biosciences). The flow data were analyzed using FlowJo v.10 (Tree Star, Inc.).

\section{Pharmacokinetic Parameters and Biodistribution in vivo}

At different points in time, post injection of the $\mathrm{Au}-\mathrm{Pt}$ NPs, $20 \mu \mathrm{L}$ of blood was drawn from the right orbital venous plexus for the Inductively Coupled Plasma Optical Emission Spectrometer (ICP-OES) analysis. The ICP-OES signals in blood samples were measured using a gamma counter. At $24 \mathrm{~h}$ post injection, the mice were sacrificed, and all major organs and tumors were collected. Then, fluorescence of organs and tumors were measured using a gamma counter. In vivo $\mathrm{CT}$ imaging, $100 \mu \mathrm{L}$ of PBS and $100 \mu \mathrm{L}$ of Au-Pt NPs $(20 \mathrm{mg} / \mathrm{kg})$ were injected into the tumor site in situ. Mice were anesthetized and scanned using a Philips CT imager. CT images were obtained from the Philips 256 CT scanning system. 


\section{Antitumor Efficacy in vivo}

The 4T1 tumor-bearing $\mathrm{BALB} / \mathrm{c}$ mice were randomly allocated to four groups: (a) control group (PBS); (b) AuPt NPs; (c) X-ray; (d) Au-Pt NPs + X-ray. When the tumor volume reached $60 \mathrm{~mm}^{3}$ at $24 \mathrm{~h}$ post-injection of PBS and Au-Pt NPs (20 mg/kg), the mice were exposed to X-ray (8 Gy). The tumor sizes and weight were recorded every other day after treatment. The mice were defined as dead when the tumor volume exceeded $1000 \mathrm{~mm}^{3}$ (Volume $=$ length*width ${ }^{2} / 2$ ). These mice were sacrificed on day 16 to collect the tumors for the hypoxia staining and crucial organs for the hematoxylin \& eosin (H\&E) staining.

The tumor tissues were removed for the frozen section. The sections were incubated overnight with an antipimonidazole mouse monoclonal antibody (100 times dilution, Hypoxyprobe Inc.). Then, an Alexa Fluo 488 conjugated goat-anti-mouse antibody (100 times dilution, Jackson Inc.) was used as the secondary antibody to combine with the primary antibody. All sections were analyzed and imaged by CLSM (OLYMPUS).

\section{Results and Discussion Synthesis and Characterization}

The synthesis procedures are shown in Scheme 1. The AuPt NPs were synthesized through a co-reduction of $\mathrm{H}_{2}$ $\mathrm{PtCl}_{6}$ and $\mathrm{HAuCl}_{4}$ by L-ascorbic acid as a chelating agent to slow down the kinetics of the reduction reaction in a one-pot method. To improve the biocompatibility of the Au-Pt NPs, polyethylene glycol (maleic anhydridealt1-octadecene) (C18-PMH-PEG $5 \mathrm{k}$ ) was used to modify it via stacking. According to the TEM mages (Figure 1A),

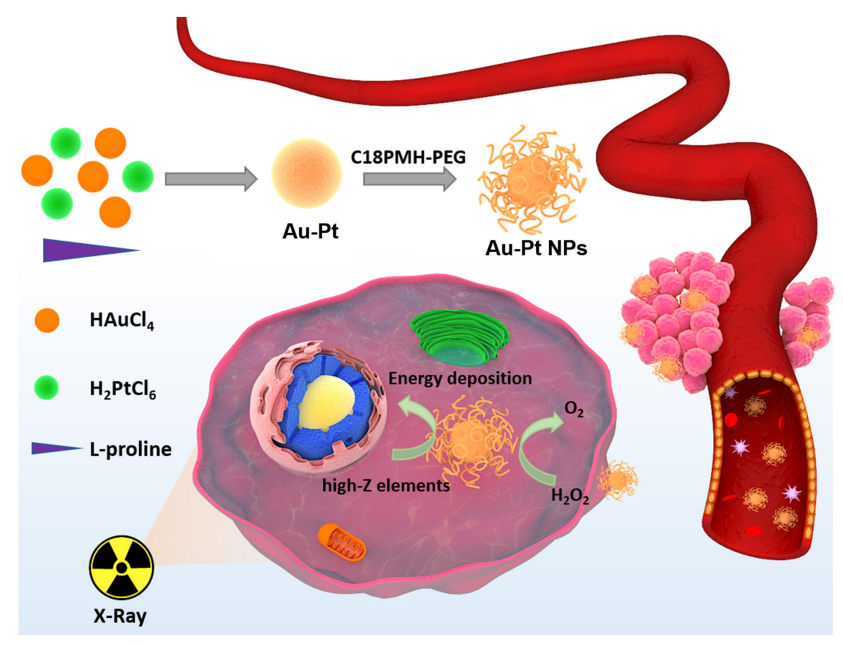

Scheme I Schematic illustrations for the fabrication of Au-Pt NPs and synergistic radiotherapy by employing tumor microenvironment. the Au-Pt NPs were uniformly dispersed and formed spherical aggregations with a diameter of about $150 \pm 20 \mathrm{~nm}$. The ultraviolet absorption spectrum showed that there was no characteristic peak of Au-Pt NPs (Figure S1). The energy-dispersive spectroscopy (EDS) elemental mapping images (Figure 1B) showed that the $\mathrm{Au}$ and $\mathrm{Pt}$ atoms were uniformly distributed in the spherical aggregations. Au and $\mathrm{Pt}$ as high atomic number elements, would absorb, scatter, and emit radiation energy to enhance the radiation dose deposition at the interface of the surrounding tissue. ${ }^{35}$ The prepared Au-Pt NPs maintained uniform dispersion and good stability in $10 \%$ fetal bovine serum (FBS), which indicated potential for its biological application (Figure 1C and E). The Zeta potential of Au-Pt $(-18.9 \mathrm{mV})$ and $\mathrm{Au}-\mathrm{Pt}$ NPs $(-21.1 \mathrm{mV})$ were similar (Figure 1D).

More importantly, we found that Au-Pt NPs catalyzed the reaction of $\mathrm{H}_{2} \mathrm{O}_{2}$ to $\mathrm{O}_{2}$. After different concentrations of Au-Pt were added to $\mathrm{H}_{2} \mathrm{O}_{2}$ solutions $(\mathrm{pH}$ 6.75) the change in the oxygen concentration was measured using a portable dissolved oxygen meter. The oxygen content did not change in the presence of only $\mathrm{H}_{2} \mathrm{O}_{2}$. However, the oxygen production rate increased gradually with an increase in the concentration of $\mathrm{Au}-\mathrm{Pt}$, which indicated the excellent CAT-like activity of Au-Pt NPs (Figures $1 \mathrm{~F}$ and $\underline{\mathrm{S}}$ ). Excessive reactive $\mathrm{O}_{2}$ species (such as $\mathrm{H}_{2} \mathrm{O}_{2}$ derived by cancer cells) is one of the oxidative stresses within the tumor microenvironment. The triggering off hypoxia stimulates autophagy and glycolysis through HIF $1 \alpha$ and NFאB signaling, which promotes tumor growth and metastasis. ${ }^{3,36}$ Increasing the decomposition of $\mathrm{H}_{2} \mathrm{O}_{2}$ in TME by various nanomaterials would increase the therapeutic effect of treating tumors with phototherapy, chemodynamic therapy, and radiotherapy. ${ }^{37,38}$

\section{In vitro Enhanced Radiotherapy}

According to the MTT assay, the Au-Pt NPs exhibited negligible toxicity to human umbilical endothelial vein cells (HUEVC) and 4T1 cells at different concentrations of Au-Pt NPs at $24 \mathrm{~h}$ after treatment (Figure 2A). Furthermore, X-Rays alone ( $0-4$ Gy) also exhibited limited toxicity to HUEVC cells and 4T1 cells (Figure 2B). On the other hand, the results showed that cells cultured without $\mathrm{Au}-\mathrm{Pt} \mathrm{NPs}$ exhibited excellent viability after irradiation with X-rays. The MTT assay revealed that Au$\mathrm{Pt}$ NPs are an excellent radiosensitizer for X-raytriggered in vitro cancer RT (Figure 2C). The relative cell viability of the 4T1 cells after irradiation and 24 $h$ after treatment with Au-Pt NPs decreased greatly 
A

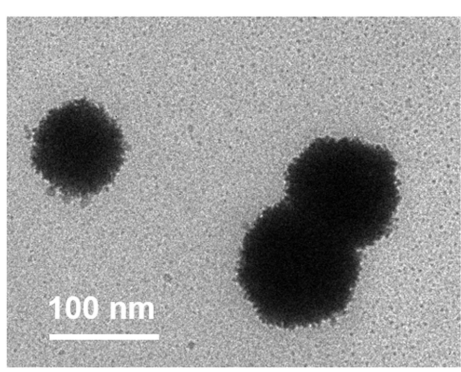

D

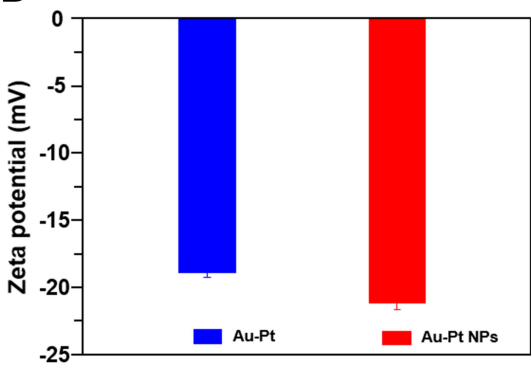

B

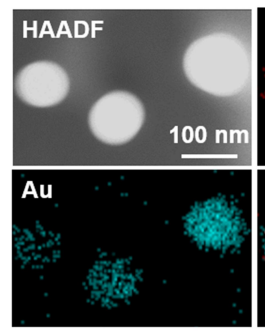

E
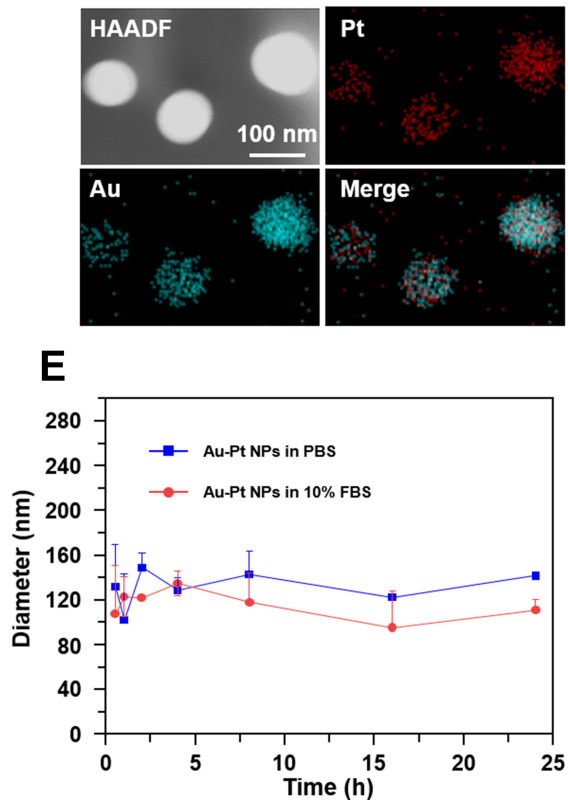

C
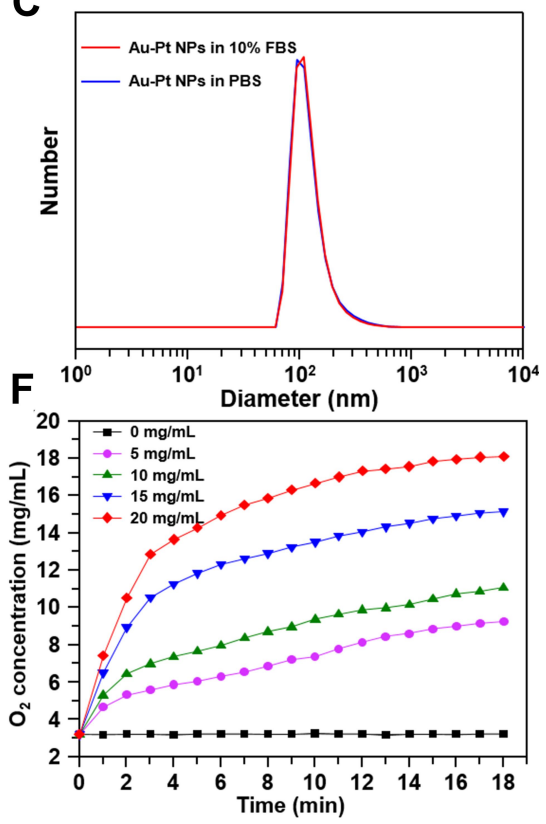

Figure I The schematic procedure and characterization of Au-Pt NPs. (A) TEM image, (B) the high-angle annular dark-field scanning transmission electron microscopy (HAADF-STEM) and elemental mapping images, (C) Hydrodynamic diameters of Au-Pt NPs in I0\% FBS and PBS measured by DLS, (D) Zeta potential of Au-Pt NPs, (E) Hydrodynamic diameters of Au-Pt NPs 10\% FBS and PBS at different times, (F) Oxygen generation in $\mathrm{H}_{2} \mathrm{O}_{2}$ solution (3.2 mM) with different concentrations of Au-Pt NPs at $\mathrm{pH} 6.75$.
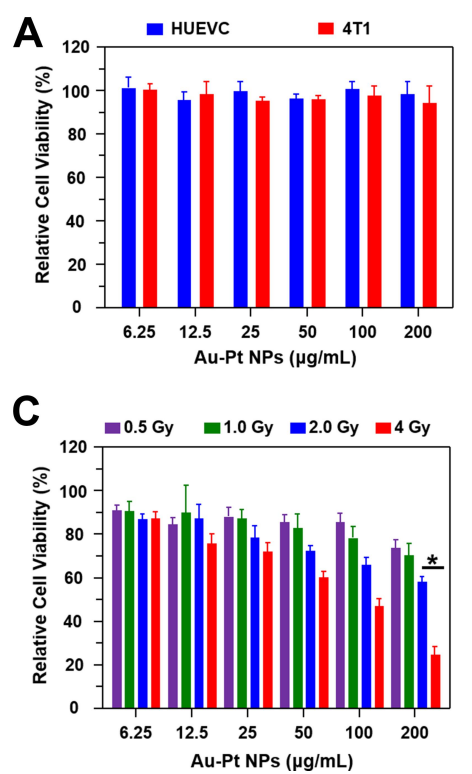

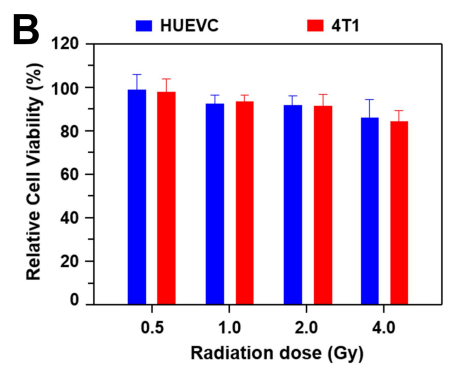

D

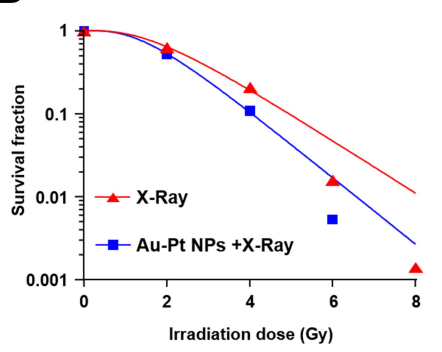

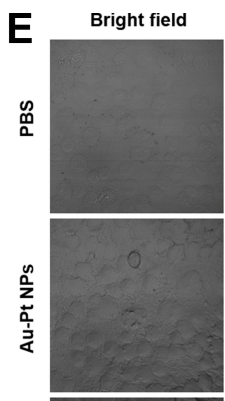
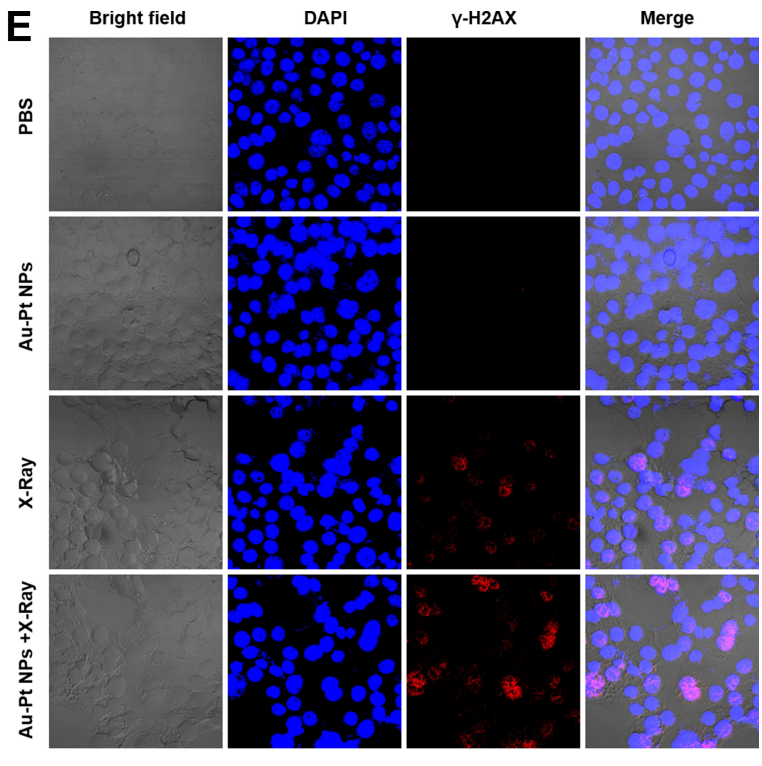

Figure 2 Relative cell viability of HUEVC cells and 4TI cells treated with Au-Pt NPs (A) and irradiation (B) for 24 h. (C) Relative cell viability of 4TI cells after irradiation for $24 \mathrm{~h}$ treated with Au-Pt NPs. (D) Clonogenic cell survival curve was generated for 4TI cells. (E) Representative immunofluorescence images of phosphorylated $\mathrm{H}_{2} \mathrm{AX}$ $\left(\gamma \mathrm{H}_{2} \mathrm{AX}\right)$ in $4 \mathrm{TI}$ cells after irradiation for $24 \mathrm{~h}$ treated with Au-Pt NPs.

compared to X-Ray treatment alone. When combined with Au-Pt NPs treatment, the relative cell viability of groups irradiated with X-rays (4 Gy) decreased to $45 \%$ (with $100 \mu \mathrm{g} / \mathrm{mL}$ Au-Pt NPs) and $22 \%$ (with $200 \mu \mathrm{g} / \mathrm{mL}$ Au-Pt NPs). The colony formation assay revealed that at the same X-ray irradiation intensity, the clone formation numbers were reduced in the presence of Au-Pt NPs, which demonstrated its enhanced antigrowth effects (Figure 2D). The double-strand DNA breaks were evaluated by $\gamma$-H2AX staining because these breaks are considered to be the major cause of X-ray induced cell death. ${ }^{39}$ Low signals of the $\gamma$-H2AX foci were detected 
for cells incubated with PBS and Au-Pt NPs alone. In contrast, a higher level of DNA damage was observed for cells irradiated with X-rays. However, cells irradiated with X-rays and treated with Au-Pt NPs appeared to have a higher level of DNA damage, which was further evidencing of the radio-sensitizing function of our nanoparticles (Figure 2E). All of these assays indicated that the cooperation of Au-Pt NPs and irradiation with X-rays can inhibit the proliferation of cancer cells.

Furthermore, the pathways of cell death were assessed using live/dead dye and the Annexin V-FITC Apoptosis Detection Kit. The $4 \mathrm{~T} 1$ cells were stained with live/dead dye as described in the surface marker staining protocol above. The signals of the PI (red) showed a dramatic increase in tumors injected with Au-Pt NPs and irradiated with X-rays compared to the tumors treated with FBS and Au-Pt NPs alone (Figure 3A). A flow cytometry-based apoptosis assay was performed to determine whether there is synergy between the Au-Pt NPs and X-rays in affecting apoptosis. The apoptosis/necrosis of the 4T1 cells treated with PBS, and X-rays were about $9.12 \%$ and $25 \%$, respectively. The apoptosis/necrosis of the combination therapy group was more than $37 \%$. Our results showed that $\mathrm{Au}-\mathrm{Pt}$ NPs significantly affect apoptosis of 4T1 cells treated with $\mathrm{X}$-rays compared with the control groups (Figure 3B and C).

\section{Pharmacokinetics and Biodistribution}

At different points in time post the intravenous injection (i.v.) of Au-Pt NPs, mouse blood samples were collected and the radioactive counts measured (Figure 4A). The nanoparticles were demonstrated to have a long blood circulation half-life $\left(\mathrm{t}_{1 / 2}=0.5 \mathrm{~h}\right)$. The ICP-MS signals were observed in many organs, especially in the liver of mice, because of the clearance of the nanoparticles by the reticuloendothelial system (RES) (Figure 4B). The tumor uptake of the Au-Pt NPs was determined to be $6.5 \% \mathrm{ID} / \mathrm{g}$ at $24 \mathrm{~h}$ post injection. We used CT imaging to study the in vivo behaviors of the Au-Pt NPs because they exhibited the ability to be detected with CT fluorescence imaging (Figure S3). Mice bearing 4T1 tumors were thus injected intravenously with Au-Pt NPs, then imaged with a CT imaging system. The timedependent increase of the CT signals (Figure 4C) was observed in the tumor after the intravenous injection with Au-Pt NPs, which indicated the efficient uptake of Au-Pt NPs by the tumor because of the EPR effect.

\section{In vivo Enhanced Radiotherapy}

Since catalase has the ability to decompose $\mathrm{H}_{2} \mathrm{O}_{2}$ to $\mathrm{H}_{2}$ $\mathrm{O}$ and $\mathrm{O}_{2}$, we assessed the ability of Au-Pt NPs to reduce tumor hypoxia in vivo using an immunofluorescent staining assay (Figure 5A). Four h post injection of different


Figure 3 (A) LIVE/DEAD staining of 4TI cells by staining with FDA (green) and PI (red) after different treatments (scale bar: $200 \mu \mathrm{m}$ ). (B, C) Flow cytometric analysis of the apoptosis of $4 \mathrm{TI}$ cells by staining with Annexin V-FITC and PI after different treatments $(* P<0.01)$. 
A

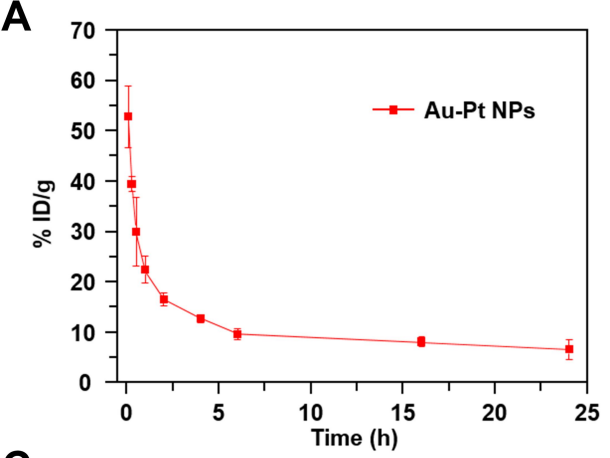

B

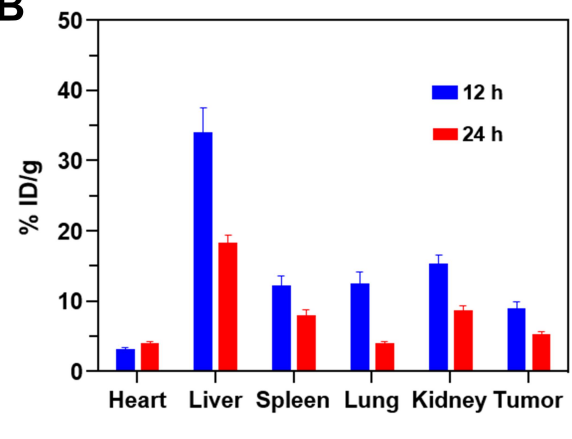

C

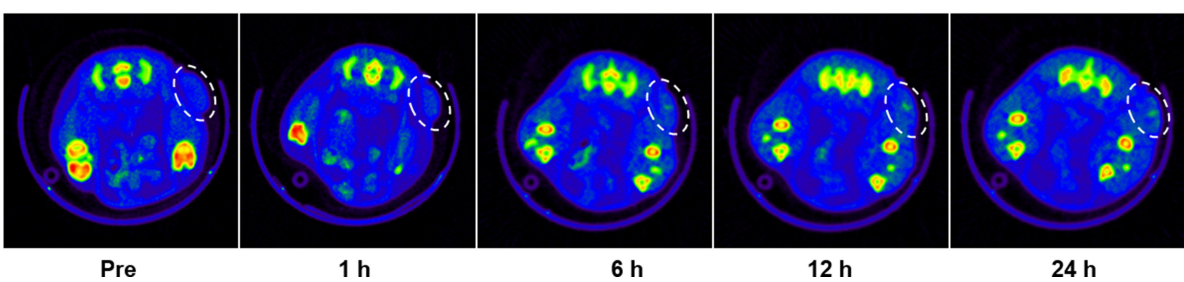

Figure 4 (A) Inductively Coupled Plasma Optical Emission Spectrometer (ICP-OES) analysis of Au-Pt NPs after tail intravenous injection for different times. (B) Organ biodistribution according to ICP-OES signal ( $N=3$ animals) with Au-Pt NPs. Data represent mean \pm s.d. (C) The thermal images of 4 TI tumor bearing mice with injection of Au-Pt NPs for different times.

nanoparticles, BALB/c mice bearing CT26 tumors were sacrificed and their tumors were collected for immunofluorescence staining. The signals of the hypoxia-probe (pimonidazole) showed a dramatic decrease in tumors injected with Au-Pt NPs because of the decomposition of $\mathrm{H}_{2} \mathrm{O}_{2}$ that generated $\mathrm{O}_{2}$ in the tumor microenvironment by the catalase loaded inside the nanoparticles. By contrast, similar to the untreated tumors, tumors from mice treated with X-rays only exhibited large hypoxic areas.

Inspired by the eminent lethality of cancer cells in vitro because of the Au-Pt NPs, the therapeutic efficacy on tumorbearing mice was then studied. The 4T1 tumor-bearing $\mathrm{BALB} / \mathrm{c}$ mice were randomly allocated to four groups: (a) control group (PBS); (b) Au-Pt NPs; (c) X-ray (8Gy); (d) AuPt NPs + X-ray. When sacrificed on day 16 , the tumors of the mice from the four groups demonstrated that the size of the tumors in the mice treated with Au-Pt NPs was smaller than in any of the other groups (Figure S4). Compared to X-ray treatment alone which resulted in only partly delayed tumor growth (Tumor volume: $459.5 \pm 76.09 \mathrm{~mm}^{3}$, Tumor weight: $0.3065 \pm 0.049 \mathrm{~g}$ ), treatment with Au-Pt NPs, at the same level of irradiation with X-rays, resulted in about a twofold increase in the inhibitory effect on the growth of the tumor (Tumor volume: $231.7 \pm 63.35 \mathrm{~mm}^{3}$, Tumor weight: 0.1662 $\pm 0.032 \mathrm{~g}$ ) (Figure $5 \mathrm{~B}$ and $\mathrm{C}$ ). In addition, the mice treated with Au-Pt NPs exhibited no loss of body weight, which indicated that there were almost no short-term side effects (Figure 5D). Moreover, the H\&E staining of the main organs from the mice showed no pathological change, which indicated that there was no poisoning of the organisms (Figure $\underline{\mathrm{S} 5}$ ). In addition, the H\&E staining was conducted to investigate any morphological changes and apoptosis of the cancer cells in the different treatment groups. As illustrated in Figure $5 \mathrm{E}$, we found that a large number of morphological changes and apoptosis of the cancer cells were dispersed throughout the whole tumor tissue from mice treated with Au-Pt NPs (Figure 5E). Taken together, the Au-Pt NPs amplified the killing effect of X-rays, which lead to the effective suppression of tumor growth without any distinct damage to surrounding non-tumor tissues.

\section{Conclusions}

In summary, we developed Au-Pt NPs via a simple method that simultaneously possesses metal nanoparticle mediated radio-sensitization, and enzyme catalytic activities. A general mechanism in nanoparticle-based radiotherapy was uncovered in that heavy metal NPs possesses a high $\mathrm{X}$-ray photon capture cross-section and Compton scattering effect which escalated the damage of DNA in tumor cells. Furthermore, our Au-Pt NPs increased the decomposition of $\mathrm{H}_{2} \mathrm{O}_{2}$ in TME and improved the anoxic status of the tumors treated with X-rays and enhanced the efficacy of radiotherapy. More importantly, in vitro, and in vivo data showed that Au-Pt NPs could effectively inhibit tumor growth with no significant side effects on normal tissues and organs. Therefore, our work developed a low toxicity novel 


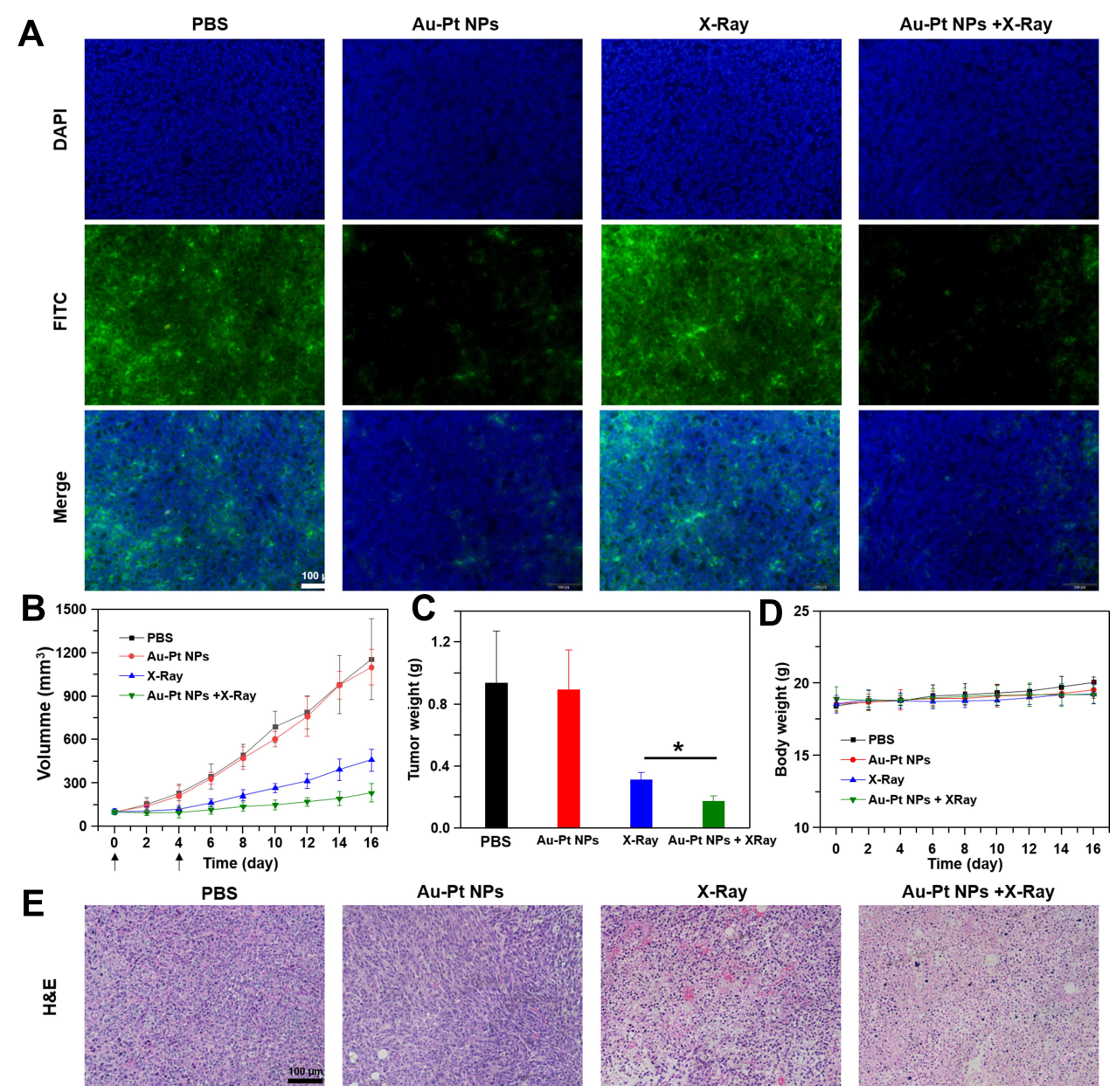

Figure 5 (A) Representative immunofluorescence images of tumor slices after hypoxia staining (scale bar: $100 \mu \mathrm{m}$ ). The hypoxia areas were stained by anti-pimonidazole antibody (green, FITC). (B) Relative tumor volume after various treatments indicated. (C) Tumor weight of sacrificed mice at Day I6 ( $* P<0.0 \mathrm{I})$. (D) Change curves for the body weight of mice. (E) H\&E staining of tumor tissues at Day 16 (scale bar: $100 \mu \mathrm{m}$ ).

radiosensitizer for enhanced tumor radiotherapy via attenuation of hypoxia. All completed clinical trials have demonstrated the safety of gold-based nanomaterials. ${ }^{40}$ In a recent clinical trial, gold-silica nanoshells (GSNs) were designed and used for ablating prostate tumors in patients without any obvious treatment-related side effects. ${ }^{41}$ Our findings further highlight the great potential application of Au-Pt NPs in the future clinical treatment of cancers.

\section{Acknowledgments}

This work was supported by the Foundation of Jiangsu Provincial Medical Innovation Team (Grant NO. CXTDA 2017042) and the Scientific Research Program of the Jiangsu Provincial Health and Family Planning Commission (H2017076).

\section{Disclosure}

The authors declare no competing interests.

\section{References}

1. Bergom C, West CM, Higginson DS, et al. The implications of genetic testing on radiation therapy decisions: a guide for radiation oncologists. Int J Radiat Oncol Biol Phys. 2019;105(4):698-712. doi:10.1016/j.ijrobp.2019.07.026

2. Moding EJ, Kastan MB, Kirsch DG. Strategies for optimizing the response of cancer and normal tissues to radiation. Nat Rev Drug Discov. 2013;12(7):526-542. doi:10.1038/nrd4003

3. Lowy DR, Collins FS. Aiming high-changing the trajectory for cancer. N Engl J Med. 2016;374(20):1901-1904. doi:10.1056/NEJMp1600894

4. Reuter S, Gupta SC, Chaturvedi MM, Aggarwal BB. Oxidative stress, inflammation, and cancer: how are they linked? Free Radic Biol Med. 2010;49(11):1603-1616. doi:10.1016/j.freeradbiomed.2010.09.006

5. Schaue D, McBride WH. Opportunities and challenges of radiotherapy for treating cancer. Nat Rev Clin Oncol. 2015;12(9):527-540. doi:10.1038/nrclinonc.2015.120

6. Phillips WT, Goins B, Bao A, et al. Rhenium-186 liposomes as convection-enhanced nanoparticle brachytherapy for treatment of glioblastoma. Neuro Oncol. 2012;14(4):416-425. doi:10.1093/ neuonc/nos060

7. Soltys KA, Setoyama K, Tafaleng EN, et al. Host conditioning and rejection monitoring in hepatocyte transplantation in humans. J Hepatol. 2017;66(5):987-1000. doi:10.1016/j.jhep.2016.12.017 
8. Sigounas DE, Krystallis C, Couper G, Paterson-Brown S, Tatsioni A, Plevris JN. Argon plasma coagulation compared with stent placement in the palliative treatment of inoperable oesophageal cancer. United European Gastroenterol J. 2017;5(1):21-31. doi:10.1177/ 2050640616650786

9. Sioulas VD, Jorge S, Chern JY, et al. Robotically assisted laparoscopic ovarian transposition in women with lower gastrointestinal cancer undergoing pelvic radiotherapy. Ann Surg Oncol. 2017;24 (1):251-256. doi:10.1245/s10434-016-5650-0

10. Mohamad O, Sishc BJ, Saha J, et al. Carbon ion radiotherapy: a review of clinical experiences and preclinical research, with an emphasis on DNA damage/repair. Cancers (Basel). 2017;9(12):66 doi:10.3390/cancers9060066

11. Mahvi DA, Liu R, Grinstaff MW, Colson YL, Raut CP. Local cancer recurrence: the realities, challenges, and opportunities for new therapies. CA Cancer J Clin. 2018;68(6):488-505. doi:10.3322/ caac. 21498

12. Miklossy G, Hilliard TS, Turkson J. Therapeutic modulators of STAT signalling for human diseases. Nat Rev Drug Discov. 2013;12 (8):611-629. doi:10.1038/nrd4088

13. Liu S-C, Alomran R, Chernikova SB, et al. Blockade of SDF-1 after irradiation inhibits tumor recurrences of autochthonous brain tumors in rats. Neuro Oncol. 2014;16(1):21-28. doi:10.1093/ neuonc/not149

14. Leontieva OV, Novototskaya LR, Paszkiewicz GM, Komarova EA, Gudkov AV, Blagosklonny MV.Dysregulation of the mTOR pathway in p53-deficient mice. Cancer Biol Ther. 2013;14(12):1182-1188. doi: $10.4161 /$ cbt.26947

15. Lambin P, van Stiphout RG, Starmans MH, et al. Predicting outcomes in radiation oncology-multifactorial decision support systems. Nat Rev Clin Oncol. 2013;10(1):27-40. doi:10.1038/ nrclinonc. 2012.196

16. Kim D, Fiske BP, Birsoy K, et al. SHMT2 drives glioma cell survival in ischaemia but imposes a dependence on glycine clearance. Nature. 2015;520(7547):363-367. doi:10.1038/nature14363

17. Xiao Y, Chen Y, Chen Y, He Z, Yao Y, Pan J. Longitudinal assessment of intravoxel incoherent motion diffusion weighted imaging in evaluating the radio-sensitivity of nasopharyngeal carcinoma treated with intensity-modulated radiation therapy. Cancer Res Treat. 2019;51(1):345-356. doi:10.4143/crt.2018.089

18. Drohat AC, Coey CT. Role of base excision "repair" enzymes in erasing epigenetic marks from DNA. Chem Rev. 2016;116 (20):12711-12729. doi:10.1021/acs.chemrev.6b00191

19. Wang H, Mu X, He H, Zhang XD. Cancer radiosensitizers. Trends Pharmacol Sci. 2018;39(1):24-48. doi:10.1016/j.tips.2017.11.003

20. Xu J, Song Z, Guo Q, Li J. Synergistic effect and molecular mechanisms of traditional Chinese medicine on regulating tumor microenvironment and cancer cells. Biomed Res Int. 2016;2016:1490738. doi:10.1155/2016/1490738

21. Tavora B, Reynolds LE, Batista S, et al. Endothelial-cell FAK targeting sensitizes tumours to DNA-damaging therapy. Nature. 2014;514 (7520):112-116. doi:10.1038/nature13541

22. Chen J, Crutchley J, Zhang D, Owzar K, Kastan MD. Identification of a DNA damage-induced alternative splicing pathway that regulates p53 and cellular senescence markers. Cancer Discov. 2017;7 (7):766-781. doi:10.1158/2159-8290.CD-16-0908

23. Lunt SJ, Cawthorne C, Ali M, et al. The hypoxia-selective cytotoxin NLCQ-1 (NSC 709257) controls metastatic disease when used as an adjuvant to radiotherapy. $B r \quad J$ Cancer. 2010;103(2):201-208. doi:10.1038/sj.bjc.6605753

24. Kaelin WG Jr., McKnight SL. Influence of metabolism on epigenetics and disease. Cell. 2013;153(1):56-69. doi:10.1016/j.cell.2013.03.004
25. Lukianova-Hleb EY, Ren X, Zasadzinski JA, Wu X, Lapotko DO. Plasmonic nanobubbles enhance efficacy and selectivity of chemotherapy against drug-resistant cancer cells. Adv Mater. 2012;24 (28):3831-3837. doi:10.1002/adma.201103550

26. Mathiyazhakan M, Wiraja C, Xu C. A concise review of gold nanoparticles-based photo-responsive liposomes for controlled drug delivery. Nanomicro Lett. 2018;10(1):10. doi:10.1007/s40820-0170166-0

27. Chow JCL. Depth dose enhancement on flattening-filter-free photon beam: a Monte Carlo Study in nanoparticle-enhanced radiotherapy. Appl Sci. 2020;10(20):7052. doi:10.3390/app10207052

28. Zheng XJ, Chow JC. Radiation dose enhancement in skin therapy with nanoparticle addition: a Monte Carlo study on kilovoltage photon and megavoltage electron beams. World J Radiol. 2017;9 (2):63-71. doi:10.4329/wjr.v9.i2.63

29. Lusic H, Grinstaff MW. X-ray-computed tomography contrast agents. Chem Rev. 2013;113(3):1641-1666. doi:10.1021/cr200358s

30. Chow JCL. Recent progress in Monte Carlo simulation on gold nanoparticle radiosensitization. AIMS Biophys. 2018;5(4):231-244. doi:10.3934/biophy.2018.4.231

31. Martelli S, Chow JCL. Dose enhancement for the flattening-filter-free and flattening-filter photon beams in nanoparticle-enhanced radiotherapy: a Monte Carlo Phantom Study. Nanomaterials (Basel). 2020;10(4):637. doi:10.3390/nano10040637

32. Siddique S, Chow JCL. Application of nanomaterials in biomedical imaging and cancer therapy. Nanomaterials (Basel). 2020;10 (9):1700. doi:10.3390/nano10091700

33. Siddique S, Chow JCL. Gold nanoparticles for drug delivery and cancer therapy. Appl Sci. 2020;10(11):3824. doi:10.3390/app1011 3824

34. Song G, Cheng L, Chao Y, Yang K, Liu Z. Emerging nanotechnology and advanced materials for cancer radiation therapy. Adv Mater. 2017;29(32). doi:10.1002/adma.201700996

35. Butterworth KT, Coulter JA, Jain S, et al. Evaluation of cytotoxicity and radiation enhancement using $1.9 \mathrm{~nm}$ gold particles: potential application for cancer therapy. Nanotechnology. 2010;21(29):295 101. doi:10.1088/0957-4484/21/29/295101

36. Dower CM, Wills CA, Frisch SM, Wang HG. Mechanisms and context underlying the role of autophagy in cancer metastasis. Autophagy. 2018;14(7):1110-1128. doi:10.1080/15548627.2018.14 50020

37. Wang M, Chang M, Chen Q, et al. Au2Pt-PEG-Ce6 nanoformulation with dual nanozyme activities for synergistic chemodynamic therapy/phototherapy. Biomaterials. 2020;252:120093. doi:10.1016/j.biomaterials. 2020.120093

38. Tong Q, Zhu Y, Galaske JW, et al. MnTE-2-PyP modulates thiol oxidation in a hydrogen peroxide-mediated manner in a human prostate cancer cell. Free Radic Biol Med. 2016;101:32-43. doi:10.1016/ j.freeradbiomed.2016.09.019

39. Wang Z, Shen W, Li X, et al. The PPARgamma agonist rosiglitazone enhances the radiosensitivity of human pancreatic cancer cells. Drug Des Devel Ther. 2020;14:3099-3110. doi:10.2147/DDDT.S242557

40. Xu J, Yu M, Peng C, et al. Dose dependencies and biocompatibility of renal clearable gold nanoparticles: from mice to non-human primates. Angew Chem Int Ed Engl. 2018;57(1):266-271. doi:10.10 02/anie.201710584

41. Rastinehad AR, Anastos H, Wajswol E, et al. Gold nanoshell-localized photothermal ablation of prostate tumors in a clinical pilot device study. Proc Natl Acad Sci U S A. 2019;116 (37):18590-18596. doi:10.1073/pnas.1906929116 
International Journal of Nanomedicine

\section{Publish your work in this journal}

The International Journal of Nanomedicine is an international, peerreviewed journal focusing on the application of nanotechnology in diagnostics, therapeutics, and drug delivery systems throughout the biomedical field. This journal is indexed on PubMed Central, MedLine, CAS, SciSearch ${ }^{\mathbb{R}}$, Current Contents ${ }^{\mathbb{B}} /$ Clinical Medicine,
Journal Citation Reports/Science Edition, EMBase, Scopus and the Elsevier Bibliographic databases. The manuscript management system is completely online and includes a very quick and fair peer-review system, which is all easy to use. Visit http://www.dovepress.com/ testimonials.php to read real quotes from published authors. 